九州大学学術情報リポジトリ

Kyushu University Institutional Repository

\title{
Measurement of QSAT Residual Magnetism
}

Ueno, Tamiki

Department of Earth and Planetary Sciences, Graduate School of Sciences, Kyushu University

Fujimoto, Akiko

Department of Earth and Planetary Sciences, Graduate School of Sciences, Kyushu University

Yumoto, Kiyofumi

Space Environment Research Center, Kyushu University

Ush i jima, Ke isuke

Department of Earth Resources Engineering, Faculty of Engineering, Kyushu University

他

https://doi.org/10.5109/11812

出版情報：九州大学大学院理学研究院紀要：Series D, Earth and planetary sciences. 32 (1)，pp.724, 2008-02-01. Faculty of Science, Kyushu University

バージョン :

権利関係 : 
Mem. Fac. Sci., Kyushu Univ., Ser. D, Earth \& Planet. Sci., Vol. XXXII, No. 1, pp. 7-23, February 1, 2008

\title{
Measurement of QSAT Residual Magnetism
}

\author{
Tamiki Ueno*, Akiko Fujimoto*, Kiyohumi Yumoto**, \\ Keisuke Ushijima $^{* * *}$, Hideki Mizunaga ${ }^{* * *}$ and Toshiya Hanada ${ }^{* * *}$
}

\begin{abstract}
The Space Environment Research Center of the Kyushu University (SERC) is developing a magnetometer which is one of the mission instrument of the Kyushu Satellite (QSAT). We must understand residual magnetism around the magnetometer in order to correctly measure the magnetic field in space. In fact, the QSAT bus system may have considerable residual magnetism. There is a possibility that this residual magnetism will have a bad effect on the mission, so we have to measure it and estimate how much effect it will have on the mission magnetometer.

For the reasons stated above, we have developed a measurement system for residual magnetism of all satellite's bus units semi-automatically. This system uses the UGF-3 magnetometer. Thanks to this instrument, it is possible to estimate residual magnetism of QSAT bus units precisely even in a regular laboratory. This system can estimate residual magnetism of a sample, if its moment is larger than $0.0001\left[\mathrm{Am}^{2}\right]$. Also, the result possesses higher reliability, if the magnetic moment is larger than $0.01\left[\mathrm{Am}^{2}\right]$.

We completed measuring eight units' residual magnetism, and we analyzed how much magnetic interference would be caused to the mission magnetometer. The results are much less than permissible levels, so magnetic interference is not a critical problem in our view.
\end{abstract}

Keywords: QSAT, Residual magnetism, Magnetic moment, Magnetic interference

\section{Introduction}

In these days, space-based infrastructure provides important contribution to our life such as the satellite broadcasting, weather forecast or the Global Positioning System and so on. However, satellites are operated in a severe environment where they are drenched in radioactive rays and high energy particles from the Sun. Therefore, it has become more and more important that we study the environment in space. The Space Environment Research Center (SERC), Kyushu University is taking part in the Kyushu Satellite (QSAT) Project. QSAT is a micro satellite as shown in Fig. 1, which is being developed by Kyushu University, Kyushu Institute of Technology, and Fukuoka Institute of Technology. Its formal nomenclature is QSAT, Polar Plasma Observation Satellite (Fig. 2 of Tsuruda et al., 2007 MS). QSAT will observe the fluctuation of the magnetic field in the

Manuscript received on 9 September 2007; accepted on 26 December 2007

* Department of Earth and Planetary Sciences, Graduate School of Science,

Kyushu University, JAPAN; t.ueno@geo.kyushu-u.ac.jp

** Space Environment Research Center, Kyushu University, JAPAN

*** Department of Earth Resources Engineering, Faculty of Engineering, Kyushu University, JAPAN

**** Department of Aeronautics and Astronautics, Faculty of Engineering, Kyushu University, JAPAN 
aurora zone, the variation of the plasma density and the spacecraft charging. The spacecraft charging sometimes breaks spacecraft down as shown in the failure of "Midori 2" in October 2003, so the primary objectives of this project are as follows: (a) investigating plasma physics in the aurora zone in order to better understand the spacecraft charging, and (b) comparing in situ observation with in ground-based observation of Field-Aligned Current (FAC), which flows into the ionosphere of polar region at the time of the substorm outbreak (Fujimoto et al., 2007).

QSAT is a 50kg-class micro satellite. Its configuration is summarized in Table 1 (Table 1 of Tsuruda et al., 2007 MS). It is equipped with magnetometer and plasma probes as mission instrument, and the SERC is in charge of the development of the magnetometer.

QSAT has a boom of about $1.5 \mathrm{~m}$ in length. The advantage with the boom is that there is less magnetic interference from the satellite bus system at the tip of the boom, where the mission magnetometer will be mounted (Fujimoto et al., 2007).

The QSAT bus system is composed of many units: the battery system, sensors, transceiver and others. They, of course, consume power, and some of them emit electromagnetic waves. These activities may create interference to the mission magnetometer, so we have to estimate the magnetic field noise at a distance of 1.5 meters from these bus units before launching so that we can perform observation in space precisely.

From the above-mentioned circumstances, we have developed a measurement system for residual magnetism. This system consists of magnetometer, rotary table, staddle, and attachment. Furthermore, we created some MATLAB programs for analysis.

Residual magnetism of satellites had been measured in the magnetic shielding room so as to reduce a magnetic field noise (Fujiwara et al., $1985 \mathrm{MS}$ ), but it was very expensive and not easy. Then in our measuring UGF-3 system, which was a magnetic field slope gage, was adopted as a residual magnetometer. Thanks to this measuring device, residual magnetism of QSAT units could be estimated precisely even in usual laboratory.

The project team is now developing the Engineering Model (EM) units. Within several months, they begin to develop Fright Model (FM) units. Residual magnetism of each unit must be estimated by the time EM unit will be accomplished. If the residual magnetism of some units creates serious magnetic interference to the mission magnetometer, we have to reduce the residual magnetism of FM units. The residual magnetic field must be less than 20nT at the tip of the boom in order to measure magnetic field variations associated with FAC 200-500nT amplitude (Hoffman et al., 1994 and Ohtani et al., 1995).

Therefore, the current main objective of measuring residual magnetism is finding the units which may have a bad effect on the mission. In this paper, we will present the principle of the residual magnetism measurement, the summary of the system and the obtained results which we have measured. Finally we discuss the actions that we should take in the future.

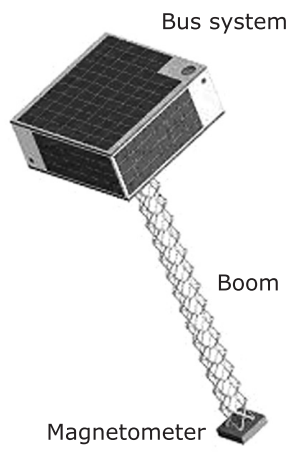

Fig. 1. Image of operational QSAT (Fig. 2 of Tsuruda et al., 2007 MS). 
Table 1. Configuration of QSAT, Polar Plasma Observation Satellite (Table 1 of Tsuruda et al., 2007 MS)

\begin{tabular}{ll}
\hline Size & $480 \times 480 \times 302[\mathrm{~mm}]$ \\
Mass & $20[\mathrm{~kg}]$ \\
Length of the boom & $1500[\mathrm{~mm}]$ \\
Consumed Power & $30[\mathrm{~W}]$ \\
Position Control & 3 axis control \\
Communication with earth frequency band & Amateur radio frequency band \\
Schedule operation period & One year \\
Orbit & Orbital height about $660 \mathrm{~km}$, synchronous sub-recurrent orbit \\
\hline & Plasma Probes (1): High-frequency probe \\
Mission instruments & Plasma Probes (2): Electric potential probe (Langmuir probe) \\
& Magnetometer: 3 axis Flux-Gate Magnetometer \\
\hline
\end{tabular}

\section{Our method of measuring residual magnetism}

In measuring residual magnetism of a satellite's bus unit, we assume that the unit has a residual magnetic dipole moment. Because the magnetic field intensity $\left(\mathrm{F}_{\mathrm{D}}=\mathrm{M}_{\mathrm{D}} / r^{3}\right)$ of magnetic dipole moment at a distance of $r$ is larger than that $\left(\mathrm{F}_{\mathrm{Q}}=\mathrm{M}_{\mathrm{Q}} / r^{4}\right)$ of quadruple moment, where $\mathrm{M}_{\mathrm{D}}$ and $\mathrm{M}_{\mathrm{Q}}$ are the dipole and quadruple moment, respectively.

The magnetic moment $M$ makes a magnetic potential $W$ at the distant of $r$ :

$$
\begin{aligned}
W & =\frac{\boldsymbol{M} \cdot \boldsymbol{r}}{r^{3}}=\frac{M}{r^{2}} \cos \left(90^{\circ}+\Phi\right) \\
& =-\frac{M}{4 \pi r^{2}} \sin \Phi
\end{aligned}
$$

Here, $\Phi$ is magnetic latitude. Then, magnetic field intensity $F, H$ and $Z$ are defined as follows (Fig. 2);

$$
\begin{aligned}
& H=-\frac{\partial W}{r \partial \Phi}=\frac{M}{4 \pi r^{3}} \cos \Phi \\
& Z=-\frac{\partial W}{\partial r}=\frac{M}{2 \pi r^{3}} \sin \Phi \\
& F=\sqrt{H^{2}+Z^{2}}
\end{aligned}
$$




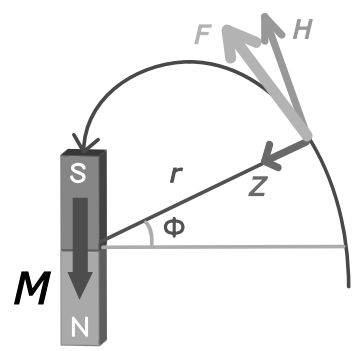

Fig. 2. Magnetic field intensity $(F, H, Z)$ at a distance of $r$ and magnetic latitude $\Phi$ from the center of magnet bar.

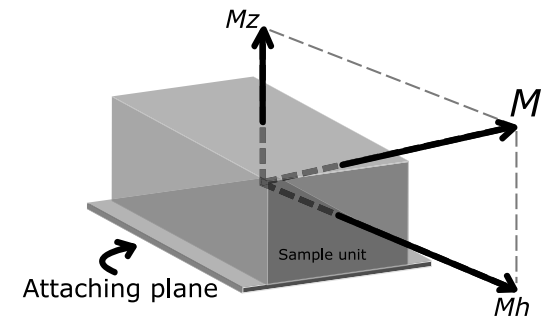

Fig. 3. The unit is assumed to have a residual magnetic dipole moment $M$, which can be decomposed to $M h$ and $\mathrm{Mz}$.

Every unit installed on the QSAT satellite is three-dimensional object as shown in Fig. 3. Now, all units are assumed to have a magnetic dipole moment $M$ as shown in the figure. $M$ can be decomposed to $M h$ and $M z . M h$ is a magnetic moment parallel to unit's attaching plane, and $M z$ is perpendicular to it. This measuring system estimates $M h$ and $M z$ by magnetic field observation, and finally combines them to calculate a composite residual magnetic moment $M$.

In estimating $M h$, a rotary table as shown in Fig. 4 (a) is used. It is turned in increments of 30 degrees, while the fixed magnetic sensor measure in situ magnetic field. This process is equal to setting up the magnetic sensors around the unit every 30 degrees (see Fig. 4 b).

(a)

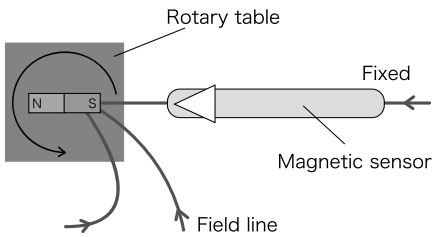

(b)

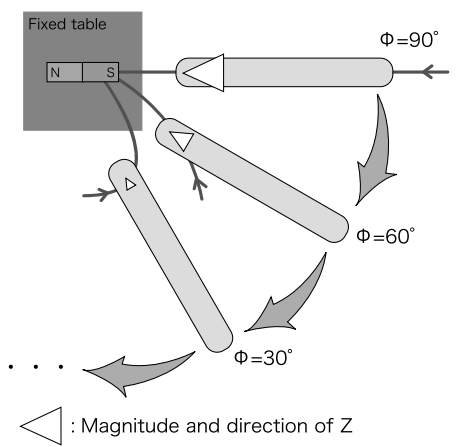

Fig. 4. (a) Turning a turntable in increments of 30 degrees is equal to (b) measuring a magnetic field around the unit every 30 degrees. Magnitude of $Z$ becomes maximum at $\Phi=90$ degrees, and the lower magnetic latitude is, the smaller magnitude of $Z$ becomes. 
We decided to turn the rotary table in increments of 30 degrees, because of shortening measuring hours and accurate estimation within $4 \%$ error of residual magnetism.

The fixed magnetic sensor measures the intensity in the radial Z-direction as shown in Figs. 2 and 4. The magnetic field $B$ in the Z-direction can be rewritten:

$$
B=\mu Z=\frac{4 \pi \times 10^{-7} M}{2 \pi r^{3}} \sin \Phi
$$

Equation (2.6) shows that $B$ depends on $\Phi . B$ becomes max at $\Phi=90$ degrees, minimum at $\Phi$ $=-90$ degrees, and the zero at $\Phi=0$ degrees. When $\Phi$ is 90 degrees at (2.6), $B$ is,

$$
B=\frac{200 M}{r^{3}} \quad[\mathrm{nT}]
$$

Also, when $\Phi$ is -90 degrees, $B$ ' is as follows.

$$
B^{\prime}=-\frac{200 M}{r^{3}} \quad[\mathrm{nT}]
$$

Figure 5 presents the measured residual magnetism of a battery system. Mh can be estimated by the top panel of magnetic variation-rotation angle records. The horizontal axis of the top panel is a degree of rotated angle, and a vertical axis is a magnetic field variations measured at the distance of $0.1 \mathrm{~m}$ from the center of the battery system. The amplitude of the top panel, which is half of a difference of $B$ between $B$ ', is equal to the maximum magnetic field range caused by $M h$.

In the case of estimating $M z$, the unit is turned 90 degrees to the magnetic sensor (see Fig. 9). The situation is equal to the case that $\Phi$ of Fig. $4 \mathrm{~b}$ is 90 degrees, i.e., a magnetic field of $\mathrm{Mz}$ is the maximum (see the bottom panel of Fig. 5). The horizontal axis of the graph is a sampling number, and a vertical axis of it is a magnetic field which is measured at the distance of $0.1 \mathrm{~m}$ from the center of the battery system. The upper line is the mean value of a magnetic field fluctuation on the condition that $\mathrm{Mz}$ exists, and the lower line is the mean value of a magnetic field fluctuation on the condition that $M z$ does not exist. The difference of two lines is equal to the maximum magnetic field that $\mathrm{Mz}$ can create. We turned the rotary table in order to estimate $M h$, and to obtain the maximum and minimum magnetic field, while we did not turn it for estimating $M z$ because $M z$ was headed for magnetic sensors from the beginning.

Using MATLAB software, we calculate $M h$ and $M z$, and combines them to estimate a composite residual magnetic moment $M$, so that is,

$$
M=\sqrt{M h^{2}+M z^{2}}
$$

Furthermore, we calculate the magnetic field of $M$ at the tip of the boom. From the estimation, we conclude whether the unit may create serious magnetic interference to the mission magnetometer or not.

\section{Experimental apparatus}

\subsection{Magnetometer: UGF-3}

The UGF-3 magnetometer was produced by TIERRA TECNICA Co. Ltd. It consists of the detecting element and the $\mathrm{A} / \mathrm{D}$ converter. Its sampling ratio is $4 \mathrm{~Hz}$. The specifications of them are summarized in Tables 2 and 3. The detecting element has three magnetic sensors at 0.45 -meter 
spacing as shown in Fig. 7. It enables measuring a magnetic field at three collinear points at the same time. The log is saved automatically with text file.
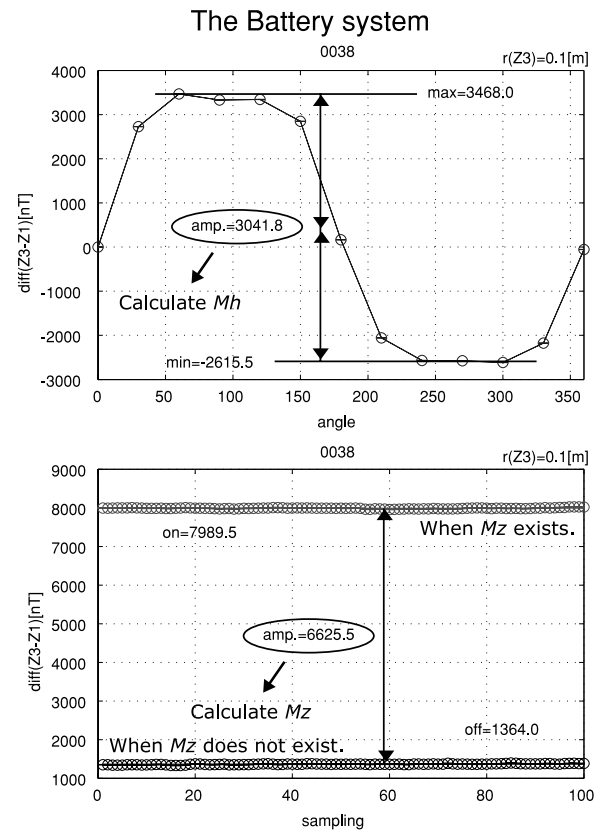

$\mathrm{Mh}=1.5209 \mathrm{e}-002\left[\mathrm{~A}^{*} \mathrm{~m}^{2}\right] \mathrm{Mz}=3.3128 \mathrm{e}-002\left[\mathrm{~A}^{*} \mathrm{~m}^{2}\right]$ totalM=3.6452e-002[ $\left[\mathrm{A}^{*} \mathrm{~m}^{2}\right]$ Magnetic field at the tip of the boom is 2.160110[nT]

Fig. 5. One example of results. $M h$ is calculated from the amplitude of the sine curve, and $M z$ is calculated from the difference of two data sets: on the condition that $M z$ exists, and $M z$ does not exist. The result shows that the battery will create about $2.16 \mathrm{nT}$ at the tip of the boom, which is over the defined permissible level.

Table 2. The detecting element specification (The instruction manual of the UGF-3).

\begin{tabular}{ll}
\hline Size & $40 \varphi \times 1100 \mathrm{~L}[\mathrm{~mm}]$ \\
Mass & $2[\mathrm{~kg}]$ \\
Materials & Vinyl chloride resin \\
Cable length & $30[\mathrm{~m}]$ \\
Sensor spacing & $450[\mathrm{~mm}]$ \\
Sensor type & Fluxgate \\
Temperature spec & $0 \sim 50[\mathrm{deg}]$ \\
Measurable range & $-100,000 \sim 100,000[\mathrm{nT}]$ \\
Limit of resolution & $1 \mathrm{nT}$ \\
Designed and produced by & TIERRA TECNICA Co. Ltd. \\
\hline
\end{tabular}


Table 3. The A/D converter specification (The instruction manual of the UGF-3).

\begin{tabular}{ll}
\hline Size & $210 \mathrm{~W} \times 230 \mathrm{D} \times 88 \mathrm{H}[\mathrm{mm}]$ \\
Mass & $3[\mathrm{~kg}]$ \\
Output & $\mathrm{RS}-232 \mathrm{C}$ \\
Interface & $4 \mathrm{~Hz}$ \\
Power supply voltage & $\mathrm{DC} 18 \mathrm{~V}$ \\
Consumed power & $2.88 \mathrm{~W}$ \\
Battery & $12 \mathrm{~V} 2.6 \mathrm{~A}$ \\
Noise & $2 \mathrm{nTp}-\mathrm{p}$ \\
Designed and produced by & TIERRA TECNICA Co. Ltd. \\
\hline
\end{tabular}

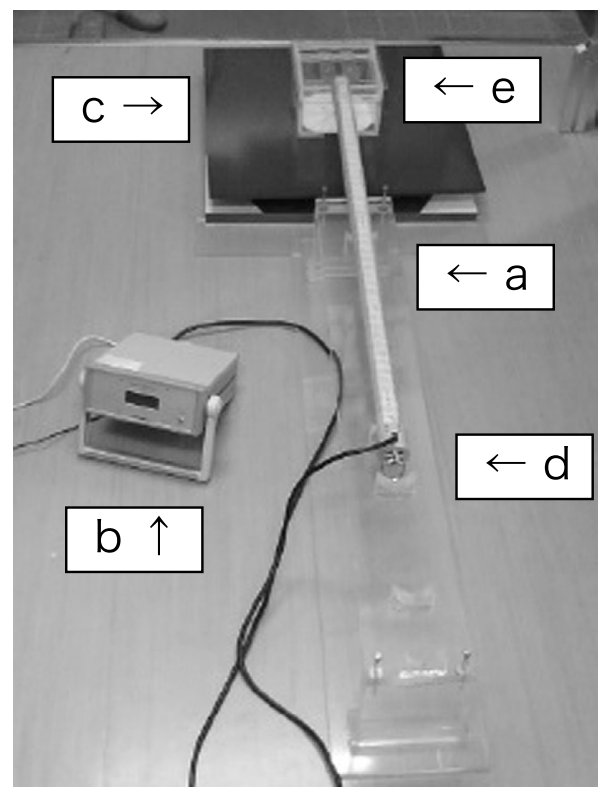

Fig. 6. Experimental apparatus. (a) Detecting element of UGF-3, (b) A/D converter of UGF-3, (c) Rotary table, (d) Staddle for magnetic sensors and (e) Attachment.

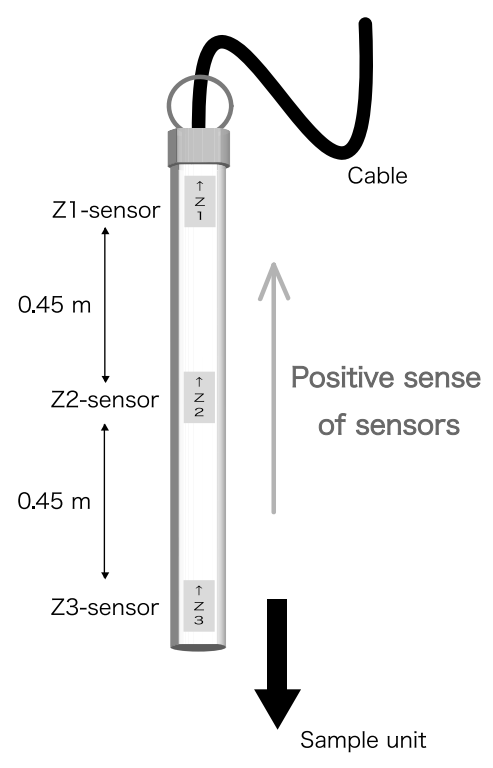

Fig. 7. A positive sence of every sensor is aimed to a cable. Z3-sensor is the closest to a sample which is put on the rotary table.

\subsection{Rotary table}

For $M h$ measurement, we need a rotary table. This rotary table is made of bakelite, brass, aluminum plates, copper and so on. They are all non-magnetic materials. Its specifications are summarized in Table 4. 
Table 4. A rotary table specification.

\begin{tabular}{ll}
\hline Size & $600 \mathrm{~W} \times 600 \mathrm{D} \times 93 \mathrm{H}[\mathrm{mm}]$ \\
Materials of top board & bakelite \\
Materials of bearing & brass, aluminum plate and copper \\
Materials of pedestal & bakelite \\
Operating & manual \\
Designed by & T. Ueno \\
Produced by & The Machine Shop, Faculty of Sciences, Kyushu University. \\
\hline
\end{tabular}

\subsection{Staddle}

A staddle for the detecting element of the UGF-3 is made of acrylate plates.

\subsection{Attachment}

For attaching fixture of samples, a rotary table is made of acrylate plate also. The rotary table, staddle, and attachment were designed by the first author and fabricated by the Machine Shop, Faculty of Sciences, Kyushu University.

\subsection{Programs}

Using MATLAB software to analyze records, we estimate $M h$ and $M z$, and calculate a composite residual magnetic moment $\mathrm{M}$ quickly. Furthermore, we presume the presence of magnetic field at the tip of the boom also. The result of analysis is printed out as shown in Fig. 5.

\section{Measurement}

In measuring, experimenters should choose as quiet laboratory as possible, where electronic products, such as a television set, an air-conditioner, an electric fan, or computers, are separated at least three meters from the magnetic sensors. Table 5 summarizes the list of QSAT bus units. Eight units had their residual magnetism measured, and the others will be measured soon. The general examination procedure is as follows. It is necessary to measure each bus unit in two statuses: (1) power on; and (2) power off. The rotary table is turned increments of 30 degrees, and the measuring time is 30 seconds per one condition.

(Put unit, when $M h$ is parallel to the rotary table.)

- Measure $M h$ in the state that the unit is resting, and measure $M h$ in the state that the unit is working. (Put unit, when $M z$ is parallel to the rotary table.)

- Measure $M z$ in the state that the unit is working, and measure $M z$ in the state that the unit is resting. 
Table 5. QSAT bus unit list.

\begin{tabular}{lll}
\hline System & Unit & Status \\
\hline & Magnetic torquer & $07 / 04 / 24$ finished \\
& Position detection and Main unit & $07 / 07 / 01$ finished \\
& Magnetic sensor unit & To be determined \\
Position control & Gyro sensor unit & $07 / 08 / 10$ finished \\
& Sun sensor unit (A) & $07 / 09 / 06$ finished \\
& Sun sensor unit (B) & $07 / 09 / 20$ finished \\
& Position control unit & To be determined \\
\hline \multirow{3}{*}{ Structure } & Body structure & To be determined \\
& Extension boom unit & To be determined \\
\hline \multirow{2}{*}{ Communication } & TNC and memory unit & $07 / 05 / 24$ finished \\
& Transceiver & $07 / 05 / 24$ finished \\
\hline \multirow{2}{*}{ Power } & Power and thermal control unit & To be determined \\
\hline
\end{tabular}

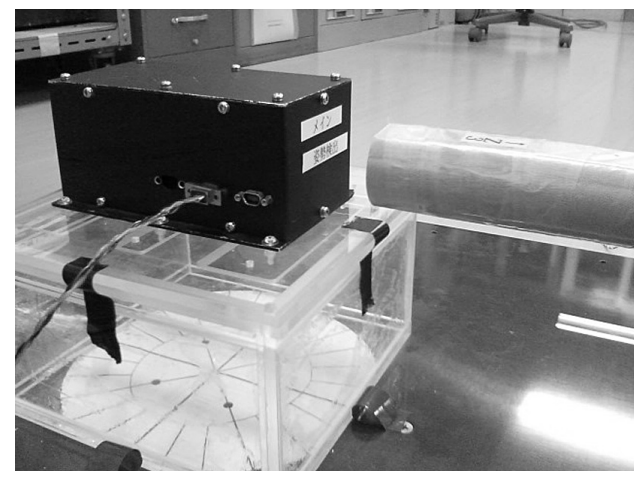

Fig. 8. The condition that $M h$ is parallel to the rotary table

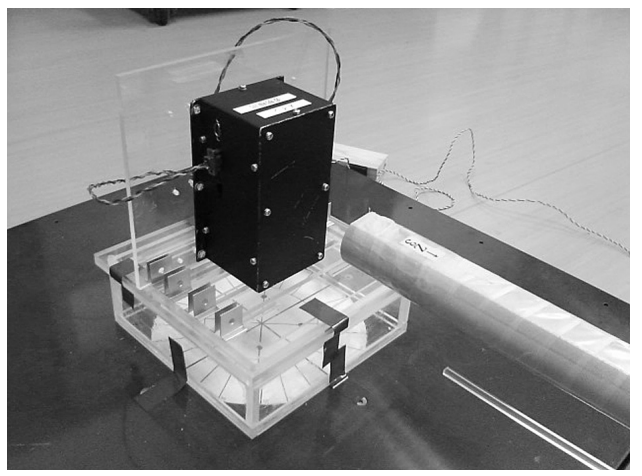

Fig. 9. The condition that $M z$ is parallel to the rotary table.

\section{Discussion}

\subsection{The method of reducing a noise}

Layout of the UGF-3 detecting element and sample unit is shown in Fig. 10. It is $0.1 \mathrm{~m}$ away from the sample unit to the Z3-sensor, and $1.0 \mathrm{~m}$ to the $\mathrm{Z} 1$-sensor. The magnetic field produced by the sample unit declines in reverse proportion to the cube of distance from the magnetic dipole moment, so a magnetic field measured at the Z1-sensor is $0.1 \%$ of that at the Z3-sensor as summarized Table 6. It is able to assume that the Z1-sensor does not pick up the residual magnetic field, therefore, the Z1-sensor can be used as a magnetometer to monitor the ambient magnetic field. The measurement error of a magnetic moment is about $0.09 \%$. 


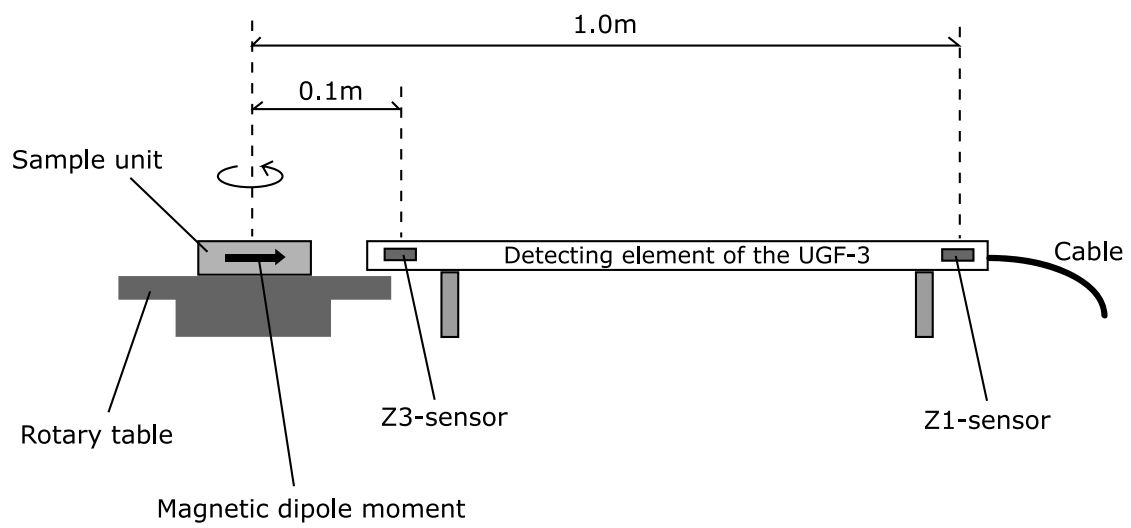

Fig. 10. The layout of the detecting element and sample unit.

Table 6. The estimation of magnetic field created by a magnetic dipole moment.

\begin{tabular}{|c|c|c|c|}
\hline \multirow{2}{*}{$\begin{array}{l}\text { Magnetic dipole moment } \\
{\left[\mathrm{Am}^{2}\right]}\end{array}$} & \multicolumn{3}{|c|}{ Magnetic field at a distance of $r$ meters from the magnetic moment [nT] } \\
\hline & $r=0.1[\mathrm{~m}]$ & $r=1.0[\mathrm{~m}]$ & $r=1.5[\mathrm{~m}]$ \\
\hline 0.001 & 200 & 0.2 & 0.059 \\
\hline 0.01 & 2,000 & 2 & 0.59 \\
\hline 0.04 & 8,000 & 8 & 2.4 \\
\hline 0.1 & 20,000 & 20 & 5.9 \\
\hline 1.0 & 200,000 & 200 & 59 \\
\hline
\end{tabular}

As shown in Fig. 11, a magnetic field caused by the sample unit can be measured by only the Z3-sensor. On the other hand, a background magnetic field noise due to the fluctuation of geomagnetic field or movement of objects and humans is measured by both sensors similarly.

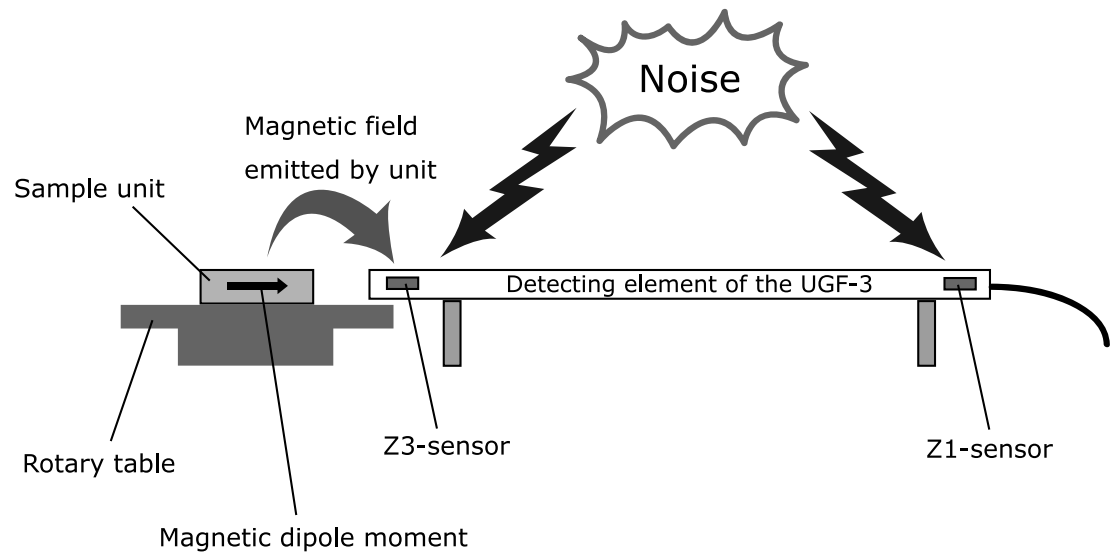

Fig. 11. The magnetic field emitted by the sample unit is measured by only the Z3-sensor, but a magnetic field noise is measured by not only the $\mathrm{Z3}$-sensor but also the $\mathrm{Z1}$-sensor. 
Figure 12 shows a process of removing the magnetic field noise from the Z3-sensor data. The figure indicates the result of the battery system.

Figure 12a is amplitude-time record measured by the Z3-sensor when $M z$ exists. Figure $12 \mathrm{~b}$ is magnetic data at the Z1-sensor. Figures. 12a-b are not constant at all, and the shape of two graphs is quite similar. It is easy to consider that the Z1-sensor and the Z3-sensor picked up the background magnetic field noise similarly. Figure $12 \mathrm{c}$ is obtained by subtracting the Z1-sensor data from the Z3sensor data and defined as "the background field cancelled data". It is clear that the prominent noise of Fig. 12a could be reduced. The magnetic moment $\mathrm{Mz}$ is obtained from the difference of magnetic field when $M z$ exist and when $M z$ does not exist. The difference of Fig. $12 \mathrm{~d}$ was 6,606.5nT, and that of Fig. 12e was 6,625.5nT. Unless the magnetic field noise was reduced, $M z$ might be underestimated.
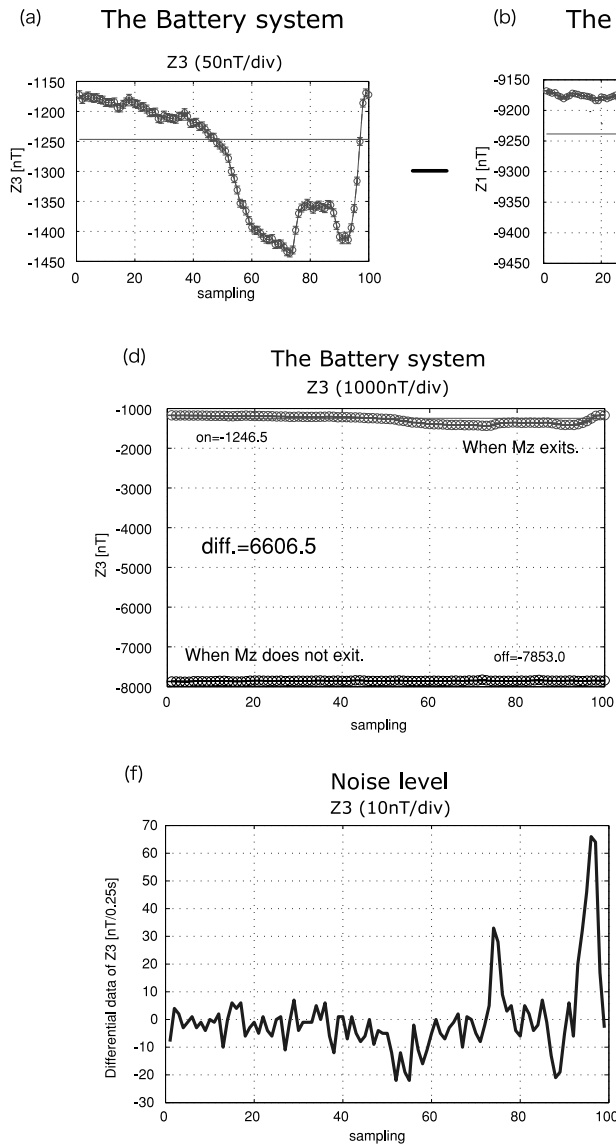

(b) The Battery system

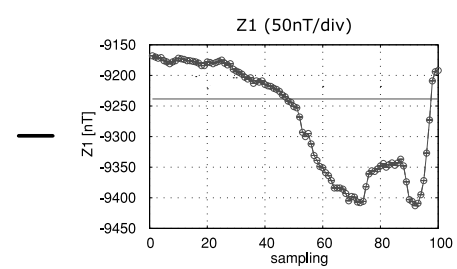

(c) The Battery system

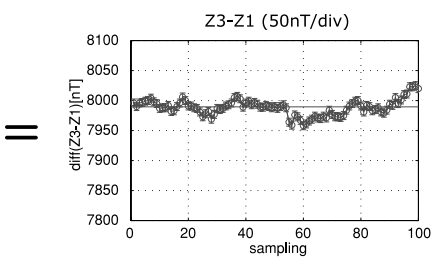

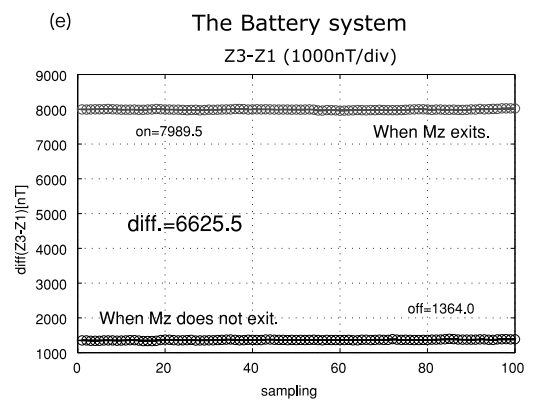

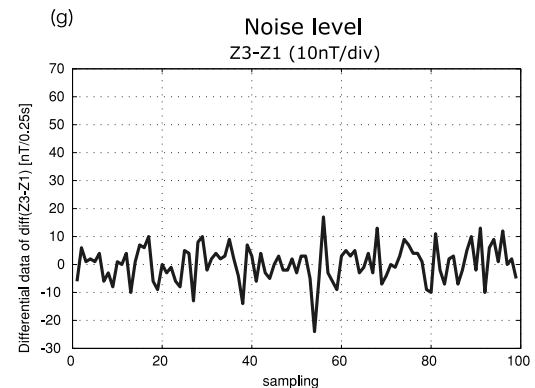

Fig. 12. (a) is the Z3-sensor data, and (b) is the Z1-sensor data. (c) is worked out by subtracting (b) from (a), so that is the background field cancelled data. (d) and (e) show the difference of magnetic field on the two conditions: $M z$ exists, or $M z$ does not exist. (d) is the simple Z3-sensor data, and (e) is calibrated Z3-sensor data. (f) and (g) show a noise level of the original Z3-sensor data and that of the background field cancelled data, respectively. 


\subsection{Analyzed Results}

We measured eight units' residual magnetism, and analyzed how much interference would be created to the mission magnetometer. The results are summarized in Tables 7-14.

Table 7. The measured result of the Magnetic torquer.

\begin{tabular}{|c|c|c|c|c|}
\hline \multirow{2}{*}{ Status } & \multicolumn{3}{|c|}{ Magnetic moment $\left[\mathrm{Am}^{2}\right]$} & \multirow{2}{*}{$\begin{array}{l}\text { A magnetic field at the tip of } \\
\text { the } 1.5 \mathrm{~m} \text { boom }[\mathrm{nT}]\end{array}$} \\
\hline & $\mathrm{Mh}$ & $\mathrm{Mz}$ & M & \\
\hline Power OFF & $3.2350 \mathrm{e}-003$ & $4.300 \mathrm{e}-004$ & $3.2635 \mathrm{e}-003$ & 0.1933 \\
\hline Power ON & $5.1534 \mathrm{e}-001$ & $2.6208 \mathrm{e}-002$ & $5.1601 \mathrm{e}-001$ & 30.578 \\
\hline
\end{tabular}

Table 8. The measured result of the Position detection and Main unit.

\begin{tabular}{|c|c|c|c|c|}
\hline \multirow{2}{*}{ Status } & \multicolumn{3}{|c|}{ Magnetic moment $\left[\mathrm{Am}^{2}\right]$} & \multirow{2}{*}{$\begin{array}{l}\text { A magnetic field at the tip of } \\
\text { the } 1.5 \mathrm{~m} \text { boom }[\mathrm{nT}]\end{array}$} \\
\hline & $\mathrm{Mh}$ & $\mathrm{Mz}$ & M & \\
\hline Power OFF & $4.7125 \mathrm{e}-004$ & $9.000 \mathrm{e}-005$ & $4.7977 \mathrm{e}-004$ & 0.0284 \\
\hline Power ON & $4.2000 \mathrm{e}-004$ & $7.500 \mathrm{e}-006$ & $4.2007 \mathrm{e}-004$ & 0.0249 \\
\hline
\end{tabular}

Table 9. The measured result of the Gyro sensor unit.

\begin{tabular}{lllll}
\hline \multirow{2}{*}{ Status } & \multicolumn{2}{l}{ Magnetic moment $\left[\mathrm{Am}^{2}\right]$} & \multicolumn{2}{l}{$\begin{array}{l}\text { A magnetic field at the tip of } \\
\text { the } 1.5 \mathrm{~m} \text { boom [nT] }\end{array}$} \\
\hline Power OFF & $1.6975 \mathrm{e}-003$ & $1.6075 \mathrm{e}-003$ & $2.3379 \mathrm{e}-003$ & 0.1385 \\
Power ON & $6.8250 \mathrm{e}-004$ & $1.4575 \mathrm{e}-003$ & $1.6094 \mathrm{e}-003$ & 0.0953 \\
\hline
\end{tabular}

Table 10. The measured result of the Sun sensor (A) unit.

\begin{tabular}{lllll}
\hline \multirow{2}{*}{ Status } & \multicolumn{2}{l}{ Magnetic moment $\left[\mathrm{Am}^{2}\right]$} & \multicolumn{2}{l}{$\begin{array}{l}\text { A magnetic field at the tip of } \\
\text { the } 1.5 \mathrm{~m} \text { boom [nT] }\end{array}$} \\
\hline Power OFF & $1.8913 \mathrm{e}-003$ & $1.6000 \mathrm{e}-004$ & $1.8980 \mathrm{e}-003$ & 0.1124 \\
Power ON & $2.0138 \mathrm{e}-003$ & $1.0000 \mathrm{e}-004$ & $2.0162 \mathrm{e}-003$ & 0.1194 \\
\hline
\end{tabular}

Table 11. The measured result of the Sun sensor (B) unit.

\begin{tabular}{lllll}
\hline \multirow{2}{*}{ Status } & \multicolumn{2}{l}{ Magnetic moment $\left[\mathrm{Am}^{2}\right]$} & & $\begin{array}{l}\text { A magnetic field at the tip of } \\
\text { the } 1.5 \mathrm{~m} \text { boom }[\mathrm{nT}]\end{array}$ \\
\hline Power OFF & $3.7125 \mathrm{e}-004$ & $1.5000 \mathrm{e}-005$ & $3.7155 \mathrm{e}-004$ & 0.0220 \\
Power ON & $4.4250 \mathrm{e}-004$ & $2.3000 \mathrm{e}-004$ & $4.9870 \mathrm{e}-004$ & 0.0296 \\
\hline
\end{tabular}


Table 12. The measured result of the TNC and memory unit.

\begin{tabular}{|c|c|c|c|c|}
\hline \multirow{2}{*}{ Status } & \multicolumn{3}{|c|}{ Magnetic moment $\left[\mathrm{Am}^{2}\right]$} & \multirow{2}{*}{$\begin{array}{l}\text { A magnetic field at the tip of } \\
\text { the } 1.5 \mathrm{~m} \text { boom }[\mathrm{nT}]\end{array}$} \\
\hline & $\mathrm{Mh}$ & $\mathrm{Mz}$ & M & \\
\hline Power OFF & $6.1625 \mathrm{e}-004$ & $1.0050 \mathrm{e}-003$ & $1.1789 \mathrm{e}-003$ & 0.0698 \\
\hline Power ON & $7.3375 \mathrm{e}-004$ & $9.9500 \mathrm{e}-004$ & $1.2363 \mathrm{e}-003$ & 0.0732 \\
\hline
\end{tabular}

Table 13. The measured result of the sum of the TNC and memory unit and Transceiver.

\begin{tabular}{|c|c|c|c|c|}
\hline \multirow{2}{*}{ Status } & \multicolumn{3}{|c|}{ Magnetic moment $\left[\mathrm{Am}^{2}\right]$} & \multirow{2}{*}{$\begin{array}{l}\text { A magnetic field at the tip of } \\
\text { the } 1.5 \mathrm{~m} \text { boom }[\mathrm{nT}]\end{array}$} \\
\hline & $\mathrm{Mh}$ & $\mathrm{Mz}$ & M & \\
\hline Power OFF & $6.0000 \mathrm{e}-004$ & $1.4825 \mathrm{e}-003$ & $1.5993 \mathrm{e}-003$ & 0.0947 \\
\hline Power ON & $1.2450 \mathrm{e}-003$ & $1.5375 \mathrm{e}-003$ & $1.9784 \mathrm{e}-003$ & 0.1172 \\
\hline
\end{tabular}

Table 14. The measured result of the Battery system. The battery system is composed of two serially connected batteries. We named them as the series- 1 and the series-2. * 1 represents that both the series- 1 and the series- 2 were not charging or discharging. *2 represents that the series- 1 was discharging. *3 represents that the series- 2 was discharging. *4 represents that the series- 1 was charging. *5 represents that the series- 2 was charging. $* 6$ represents that both the series- 1 and the series- 2 were not charging or discharging. (Both series were full completely) *7 represents that both the series- 1 and the series- 2 were not charging or discharging, and the series- 1 was turned 180degree.

\begin{tabular}{|c|c|c|c|c|}
\hline \multirow{2}{*}{ Status } & \multicolumn{3}{|c|}{ Magnetic moment $\left[\mathrm{Am}^{2}\right]$} & \multirow{2}{*}{$\begin{array}{l}\text { A magnetic field at the tip of } \\
\text { the } 1.5 \mathrm{~m} \text { boom }[\mathrm{nT}]\end{array}$} \\
\hline & $\mathrm{Mh}$ & $\mathrm{Mz}$ & M & \\
\hline$* 1$ & $1.5209 \mathrm{e}-002$ & $3.3128 \mathrm{e}-002$ & $3.6452 \mathrm{e}-002$ & 2.1601 \\
\hline$*_{2}$ & $1.5164 \mathrm{e}-002$ & $3.1975 \mathrm{e}-002$ & $3.5388 \mathrm{e}-002$ & 2.0971 \\
\hline *3 & $1.5218 \mathrm{e}-002$ & $3.2065 \mathrm{e}-002$ & $3.5493 \mathrm{e}-002$ & 2.1033 \\
\hline$* 4$ & $1.5243 \mathrm{e}-002$ & $3.0540 \mathrm{e}-002$ & $3.4132 \mathrm{e}-002$ & 2.0227 \\
\hline *5 & $1.5272 \mathrm{e}-002$ & $3.1708 \mathrm{e}-002$ & $3.5195 \mathrm{e}-002$ & 2.0856 \\
\hline *6 & $1.5295 \mathrm{e}-002$ & $3.2375 \mathrm{e}-002$ & $3.5806 \mathrm{e}-002$ & 2.1218 \\
\hline *7 & $1.0418 \mathrm{e}-002$ & $4.9900 \mathrm{e}-003$ & $1.1551 \mathrm{e}-002$ & 0.6845 \\
\hline
\end{tabular}

From the results, we conclude:

(1) Position detection and Main unit, Gyro sensor unit, Sun sensor unit (A), Sun sensor unit (B), $\mathrm{TNC}$ and memory unit, and Transceiver have little influence on the mission magnetometer.

(2) Magnetic torquer has rather serious effect on the mission when it is at work, but the project team determined that they will disable the magnetic torquer during the mission. Therefore, it has little influence on the mission magnetometer. Damping time of magnetic torquer ought to be taken account.

(3) Though the battery system has rather large magnetic moment, the magnetic field caused by the battery system is generally constant in any event. Therefore, we can regard magnetic field caused by the battery system as a magnetic field bias. The battery system is composed of two serially connected batteries. When the one series connection was turned 180 degrees (see Fig. 13b), its residual magnetism became about 30\% of the previous one. The result suggests that reversing twin polarities each other is effective in reducing residual magnetism. 

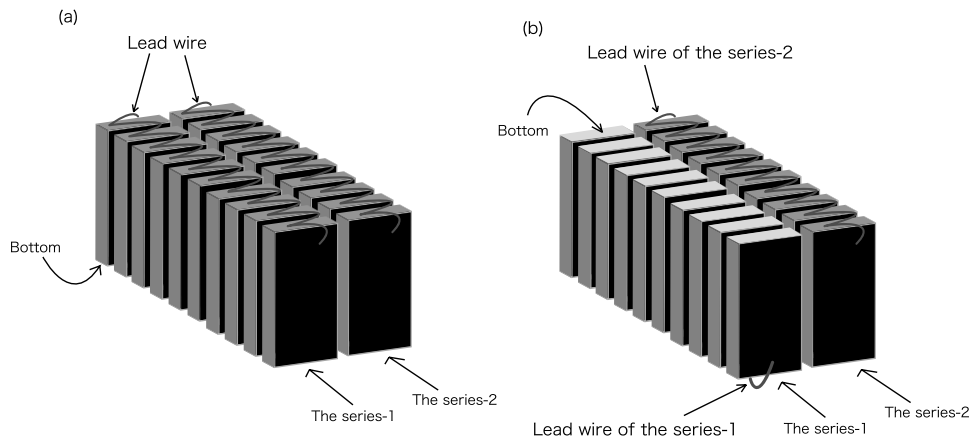

Fig. 13. The battery system is composed of two series connections of batteries. One series connection is consists of ten batteries. When the one series connection was turned 180 degrees as shown in (b), its residual magnetism became about $30 \%$ of (a).

\subsection{The assumption and margin of error}

The results have some margin of error, because all sample units are assumed to have a residual magnetic dipole moment at the center of them. From the top panel of Fig. 5, we notice that the numerical value of the maximum is not equal to that of the minimum. There are two possibilities about the position of the magnetic dipole moment. The one possibility is as shown in Fig. 14a. In this case, at 0 degree, the magnetic moment heads for magnetic sensors but it is not at the center of the unit. Another is as shown in Fig. 14b. In this case, though the magnetic moment is at the center of the unit, it does not head for magnetic sensors. If the situation is the former, length from the ideal position of the magnetic moment (it is the center of the unit) to the real position should be taken account in a narrow sense. However, if the length is less than $13 \mathrm{~mm}$, the measurement error of a magnetic moment is less than $10 \%$. In the case of the battery system, if the situation is like Fig. 14b, anticipated shift length is about $4.7 \mathrm{~mm}$, and the measurement error is less than $1.5 \%$. Therefore, it is reasonable that the position of the magnetic moment is looked upon as at the center of the battery system.

\section{at 0 degree}

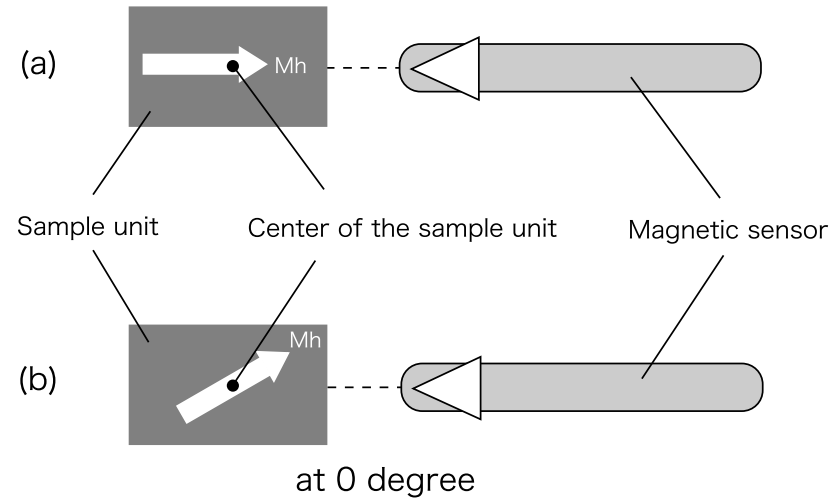

Fig. 14. Two possibilities about the position of the magnetic dipole moment. In the case of (a), at 0 degree, the magnetic moment heads for magnetic sensors but it is not at the center of the unit. In the case of (b), though the magnetic moment is at the center of the unit, it does not head for magnetic sensors. 
In estimating $M h$, its graph does not always become a clear sine curve. There are some possibilities about this problem:

(1) Influence of background magnetic field noise. If the sample unit has small magnetic moment, it hardly creates magnetic field variation, so the graph has an unclear shape. Details will be explained in the next paragraph.

(2) Influence of the quadruple magnetic moment. In such a case, we can get clear sine curve by detaching detecting element from the sample unit. That is because the magnetic field intensity $\left(\mathrm{F}_{\mathrm{D}}=\mathrm{M}_{\mathrm{D}} / r^{3}\right)$ of magnetic dipole moment at a distance of $r$ is larger than that $\left(\mathrm{F}_{\mathrm{Q}}=\mathrm{M}_{\mathrm{Q}} / r^{4}\right)$ of quadruple moment, where $\mathrm{M}_{\mathrm{D}}$ and $\mathrm{M}_{\mathrm{Q}}$ are the dipole and quadruple moment, respectively.

(3) Influence of the multiple magnetic dipole moments. The result of the battery system (the top panel in Fig. 5) looks like mixture of a sine curve and a pulse shape. It is probable that multiple magnetic dipole moments create a complicated magnetic field. In such a case, we regard them as one dipole moment, so we do not take account of multiple magnetic dipole moments now. The measurement error of a magnetic moment occurred by this approximation has not been assessed yet.

\subsection{The limit of measurement and accuracy of our results}

This measurement system subtracts prominent noise of background magnetic field from the Z3sensor data, but small fluctuation of background magnetic field remains. Figures. 12f-g show a noise level of the original Z3-sensor data and that of the background field cancelled data. The former is about $-20-60 \mathrm{nT}$, and the latter is about $-10-10 \mathrm{nT}$. The result shows that a noise level is cut down nearly $50 \%$ by subtracting the Z1-sensor data from the Z3-sensor data. However, it is difficult for this measurement system to estimate very small (less than $0.001\left[\mathrm{Am}^{2}\right]$ ) residual magnetism. If amplitude of magnetic field variation is less than $20 \mathrm{nT}$ at a distance of $0.1 \mathrm{~m}$ from the unit, this system cannot estimate the magnetic moment. The $20 \mathrm{nT}$ at $0.1 \mathrm{~m}$ is caused by $0.0001\left[\mathrm{Am}^{2}\right]$, so it is the minimum limit of measurement.

Table 15 is an estimation of the reliability of our result. Reliability of the result is dependent on amplitude of magnetic field variation caused by a magnetic moment. The result possesses higher reliability, if the magnetic moment is larger than $0.01\left[\mathrm{Am}^{2}\right]$. If a magnetic moment is less than 0.01 $\left[\mathrm{Am}^{2}\right]$, magnetic interference to the mission caused by the magnetic moment is no problem. Therefore, this measurement system has adequate accuracy.

In estimating very small residual magnetism (less than $0.001\left[\mathrm{Am}^{2}\right]$ ), we should be concerned about magnetic environment of experiment station. As much as possible, this measurement must be done where there is no noise.

Table 15. The estimation of reliability of a result.

\begin{tabular}{lrrrr}
\hline $\begin{array}{l}\text { Mangetic moment } \\
{\left[\mathrm{Am}^{2}\right]}\end{array}$ & $\begin{array}{r}\text { Magnetic field } \\
\text { at } r=0.1 \mathrm{~m}[\mathrm{nT}]\end{array}$ & $\begin{array}{r}\text { The error range of } \\
\text { Magnetic field [nT] }\end{array}$ & $\begin{array}{r}\text { The error range of } \\
\text { Magnetic moment }\left[\mathrm{Am}^{2}\right]\end{array}$ & $\begin{array}{r}\text { Reliability of a } \\
\text { result [\%] }\end{array}$ \\
\hline 0.0001 & 20 & $10 \sim 30$ & $0.00005 \sim 0.00015$ & 50.0 \\
0.001 & 200 & $190 \sim 210$ & $0.00095 \sim 0.00105$ & 95.0 \\
0.01 & 2000 & $1990 \sim 2010$ & $0.00995 \sim 0.01005$ & 99.5 \\
0.1 & 20000 & $19990 \sim 20010$ & $0.0995 \sim 0.10005$ & 99.9 \\
\hline
\end{tabular}




\section{Conclusions}

We have developed the measurement system of residual magnetism for QSAT, and some of units were already measured. Thanks to the UGF-3, it is possible to estimate residual magnetism of QSAT bus units precisely even in a regular laboratory. It is an advantage that the UGF-3 has three collinear magnetic sensors. The Z3-sensor, which is the nearest to the sample, picks up not only a magnetic field caused by the sample unit but also a background magnetic field noise. On the other hand, the Z1-sensor, which is the most distant from the sample, picks up only a background magnetic field noise. By subtracting the Z1-sensor data from the Z3-sensor data, we can remove a background magnetic field noise from the Z3-sensor data.

We gave an assessment of this measuring system. This system can estimate residual magnetism of a sample unit, if its moment is larger than $0.0001\left[\mathrm{Am}^{2}\right]$. Also, the result possesses higher reliability, if the magnetic moment is larger than $0.01\left[\mathrm{Am}^{2}\right]$. Current main objective of measuring residual magnetism is finding units may have a bad effect on the mission (such a magnetic moment is over $\left.0.01\left[\mathrm{Am}^{2}\right]\right)$, so this system has adequate accuracy.

From the results of measuring eight units' residual magnetism, total magnetic field created by QSAT bus units at the tip of the boom is estimated at about 3.1nT (Magnetic torquer: OFF, Position detection and Main unit: OFF, Gyro sensor unit: OFF, Sun sensor unit (A): ON, Sun sensor unit (B): ON, TNC and memory unit: ON, Transceiver: ON, Battery system: two serially connected batteries are not twisted and they are not charging or discharging). The estimation is much less than permissible magnetic field noise level (20nT), so magnetic interference to the mission magnetometer is not a critical problem in our view.

We are now measuring residual magnetism of EM (Engineering Model) units, which will be finished measuring before long, so the next step is measuring residual magnetism of all FM (Flight Model) units. In measurement of residual magnetism of FM units, we should take the real position of residual magnetic moment into consideration. (Now we assume that a residual magnetic moment is at the center of a sample unit.) Also, it is necessary to prepare less magnetically noisy environment so that we can estimate small magnetic moment more precisely.

\section{Acknowledgments}

A draft of this paper was critically reviewed, so we thank the reviewer. The UGF-3 is supplied by Prof. Keisuke Ushijima and Prof. Hideki Mizunaga. We are grateful to Dr. Shuji Abe, Dr. Manabu Shinohara of Space Environment Research Center, Kyushu University, Mr. Yoshihiro Tsuruda (Student Manager of the QSAT project) of Faculty of Engineering, Kyushu University, and the staff of the machine shop attached to Department of Science, Kyushu University for their technical assistance in developing the measurement system of residual magnetism, Finally, Mr. George Maeda of Space Environment Research Center, Kyushu University, who proofread a draft of this paper, is gratefully appreciated. 


\section{References}

Fujimoto, A. (2007 MS) Mission requirement. QSAT management document 070610.

Fujimoto, A. and Yumoto, K. (2007 MS) Payroad instrument. QSAT review document. Chapter8.

Fujimoto, A. Ueno, T and Yumoto, K. (2007) A science mission for QSAT project - Study of FACs in the polar and equatorial regions -, submitted to Earth, Moon and Planet.

Fujiwara, K., Aoyama, I. and Hirao, K. (1985 MS) Precise measurement of residual magnetism of satellite in magnetic shielding room, The master's thesis of Department of Aeronautics and Astronautics, Faculty of Engineering, Tokai University.

Hoffman, R. A., Fujii, R. and Sugiura, M. (1994) Characteristics of the field-aligned current system in the region the nighttime sector during auroral substorms, Journal of Geophysical Research, 99, A11, 20303-21325.

Ohtani, S., Potemra, T. A., Newell, P. T., Zanetti, L. J., Iijima, T., Watanabe, M., Yamauchi, M., Elphinstone, R. D., O. de la Beaujardiere, and Blomberg, L. G. (1995) Simultaneous prenoon and postnoon observations of three field-aligned current system from Viking and DMSP-F7, Journal of Geophysical Research, 100, A1, 119-136.

Tsuruda, Y., Fujimoto, A., Kurahara, N., Yumoto, K., Hanada, T. and Cho, M. (2007) QSAT the satellite for polar plasma observation, submitted to Astrophysics and Space Science.

Tsuruda, Y. and Hanada, T. (2007 MS) System overview. QSAT review document. Chapter1. 
